\title{
Fertility and pregnancy outcomes following uterine artery embolization (UAE) for uterine arteriovenous malformation (AVM)
}

\author{
Angelos G. Vilos • George A. Vilos • Barbara de Vrijer • \\ Roman Kozak • Basim Abu-Rafea
}

Received: 28 April 2009/Accepted: 20 June 2009 / Published online: 9 July 2009

(C) Springer-Verlag 2009

\begin{abstract}
A 19-year-old patient presented with intractable uterine bleeding, 11 weeks post-abortion. A pelvic ultrasound with Doppler and color imaging suggested a uterine arteriovenous malformation. Failing conservative therapies, the patient consented to uterine artery embolization (UAE). Two months later, she conceived and had an uneventful normal vaginal delivery at term. Since this is an extremely rare condition, allowing limited clinical exposure and experience, there may be an underlying reluctance by general practitioners to treat these cases with uterine artery embolization for fear of compromising future fertility and pregnancies. However, data from the 20 pregnancies embolized for uterine AVM cited in the present report and data from embolization for uterine fibroids indicate that such fears may be unfounded since pregnancy rates and outcomes may not be compromised after UAE.
\end{abstract}

\footnotetext{
A. G. Vilos $\cdot$ G. A. Vilos $(\bowtie) \cdot$ B. de Vrijer

Department of Obstetrics and Gynecology, St. Joseph's Health

Care,

268 Grosvenor St.,

London, ON, Canada N6A 4V2

e-mail: george.vilos@sjhc.london.on.ca

R. Kozak

Radiology, The University of Western Ontario,

London, ON, Canada

B. Abu-Rafea

King Saud University,

Riyadh, Saudi Arabia
}

Keywords Menorrhagia - Arteriovenous malformation . Uterine artery embolization · Pregnancy

\section{Introduction}

Uterine arteriovenous malformations (AVM) are extremely rare and may be either congenital or acquired through trauma, uterine instrumentation such as $\mathrm{D} \& \mathrm{C}$, infection or gestational trophoblastic disease. They may present as menorrhagia, menometrorrhagia or sudden and sometimes severe uterine bleeding or post-partum hemorrhage [1-3]. There is evidence to suggest that arteriovenous malformations may be a cause of recurrent pregnancy loss [4, 5]. Traditionally, therapies include medical management of symptomatic bleeding [6], blood transfusions for more severe episodes of hemorrhage, or uterine artery embolization (UAE) with either microsphere particles or gelfoam pledgets. A case of UAE followed by laparoscopic resection of the mass has also been reported [7]. In cases where UAE is not available or not logistically feasible, hysterectomy has been the definitive standard of practice. However, in women who wish to preserve their fertility or cannot tolerate surgery, hysterectomy may not be desirable or feasible and uterine artery embolization is an acceptable treatment option. To date, we found 15 reports describing 19 pregnancies following uterine artery embolization for the treatment of arteriovenous malformation [3, 5, 7-19] (Table 1).

To our knowledge, our case is the first of its kind in Canada and one of the youngest patients to have a successful pregnancy soon after uterine artery embolization 
Table 1 Patient characteristics, embolization techniques, mode of delivery and outcomes

\begin{tabular}{|c|c|c|c|c|c|c|c|c|c|}
\hline Author & $\begin{array}{l}\text { Patient } \\
\text { age }\end{array}$ & Parity & $\begin{array}{l}\text { Embolization } \\
\text { material }\end{array}$ & Type of Delivery & Gestation & Comments & $\begin{array}{l}\text { Fetal } \\
\text { weight }\end{array}$ & & Placenta \\
\hline $\begin{array}{c}\text { Chapman } \\
1985\end{array}$ & 28 & G1P0 & Coils $+\mathrm{RP}$ & $\begin{array}{l}\text { Emergency cesarean } \\
\text { section }\end{array}$ & 32 weeks & $\begin{array}{l}\text { Placenta } \\
\text { Previa }\end{array}$ & 1,240 & g & Previa \\
\hline $\begin{array}{r}\text { Poppe } \\
1986\end{array}$ & 25 & G1P0 & $\mathrm{NRP}+\mathrm{RP}$ & Vaginal & 35 weeks & None & 2,600 & $\mathrm{~g}$ & Normal \\
\hline $\begin{array}{r}\text { Tacchi } \\
1988\end{array}$ & 30 & G1P0 & $\begin{array}{l}\text { Coils +NRP+ } \\
\text { RP }\end{array}$ & $\begin{array}{l}\text { Emergency cesarean } \\
\text { section }\end{array}$ & 30 weeks & AFHR & 1,389 & $\mathrm{~g}$ & $\begin{array}{l}\text { Ischemic } \\
\text { areas }\end{array}$ \\
\hline $\begin{array}{c}\text { Beller } \\
1988\end{array}$ & 25 & G0 & $\mathrm{I} 2 \mathrm{C}$ & Cesarean section & Term & None & NA & & NA \\
\hline $\begin{array}{l}\text { Chow } \\
1995\end{array}$ & 18 & G1P0 & $\mathrm{NRP}+\mathrm{RP}$ & Vaginal & $\begin{array}{l}40+3 \\
\text { weeks }\end{array}$ & $\begin{array}{l}\text { blood loss } \\
1 \mathrm{~L}\end{array}$ & 3,962 & $\mathrm{~g}$ & Normal \\
\hline $\begin{array}{l}\text { Gaens } \\
1996\end{array}$ & 27 & G6P1 & $\mathrm{I} 2 \mathrm{C}$ & N/A & $\begin{array}{l}341 / 2 \\
\text { weeks }\end{array}$ & NA & NA & & NA \\
\hline $\begin{array}{c}\text { Zanetta } \\
1997\end{array}$ & 24 & G0 & NRP & Vaginal & Term & None & NA & & NA \\
\hline $\begin{array}{l}\text { Kelly } \\
2001\end{array}$ & 30 & G4P0 & Coils+NRP & Vaginal, forceps & 32 weeks & AFHR & 1,565 & $\mathrm{~g}$ & $\begin{array}{l}\text { AVM } \\
\text { persistent }\end{array}$ \\
\hline Lim 2002 & $\begin{array}{l}2 \text { patients, } \\
\text { N/A }\end{array}$ & NA & NRP & 3 pregnancies, N/A & Term $\times 3$ & Live births $\times 3$ & NA & & NA \\
\hline $\begin{array}{r}\text { Gopal } \\
2003\end{array}$ & 42 & G5P2 & $\mathrm{NRP}+\mathrm{RP}$ & Cesarean section & 37 weeks & Twins & $\begin{array}{l}3,081 \\
2,935\end{array}$ & $\begin{array}{r}\mathrm{g}, \\
\mathrm{g}\end{array}$ & NA \\
\hline $\begin{array}{l}\text { Chia } \\
2003\end{array}$ & 37 & G3P2 & $\mathrm{I} 2 \mathrm{C}$ & Cesarean section & 39 weeks & None & 3,500 & $\mathrm{~g}$ & NA \\
\hline $\begin{array}{r}\text { Garner } \\
2003\end{array}$ & 32 & G0 & NRP & Vaginal, forceps & $\begin{array}{l}40+1 \\
\text { weeks }\end{array}$ & None & 2,830 & g & NA \\
\hline $\begin{array}{l}\text { Amagada } \\
2004\end{array}$ & 17 & G1P0 & NRP & Vaginal & 37 weeks & None & 3,440 & g & Normal \\
\hline $\begin{array}{l}\text { Delotte } \\
2006\end{array}$ & 33 & $\mathrm{G} 2 \mathrm{P} 1$ & Coils + I2C & Vaginal & $\begin{array}{l}36+5 \\
\text { weeks }\end{array}$ & None & 3,040 & $\mathrm{~g}$ & Normal \\
\hline Tsai 2006 & 31 & G8P4 & $\mathrm{I} 2 \mathrm{C}$ & Vaginal & 39 weeks & None & NA & & NA \\
\hline $\begin{array}{l}\text { Hasegawa } \\
2008\end{array}$ & 34 & G0 & NRP & Cesarean section & Term & None & NA & & NA \\
\hline Our case & 19 & G1P0 & $\mathrm{RP}+\mathrm{NRP}$ & Vaginal & 39 weeks & None & 2,940 & $\mathrm{~g}$ & Normal \\
\hline
\end{tabular}

$R P$ resorbable particles, $N R P$ nonresorbable particles, $I 2 C$ mixed isobutyl-2-cyanoacrylate+lipiodol, $N A$ not available

for the treatment of arteriovenous malformation. Review of the case has been granted by our local ethics committee and the patient has signed consent.

\section{Case report}

A 19-year-old patient, para 0, gravida 1, presented for evaluation of persistent vaginal bleeding. She had a therapeutic abortion at 11 weeks gestation by suction curettage 3 months prior to her visit and had been bleeding quite heavily since. A pelvic ultrasound with Doppler and color imaging suggested an arteriovenous malformation measuring approximately $1.9 \mathrm{~cm}$. Trials of tranexamic acid (Cyclokapron, Pfizer, New York, NY, USA), oral contraceptives, and a Foley catheter inserted to tamponade the uterus on two occasions failed or was not tolerated by the patient. At one point, the patient received blood transfusion and hysterectomy was considered as definitive treatment in a peripheral hospital.

The patient was transferred to a tertiary center. Uterine artery embolization was explained to the patient including possible procedural risks as well as uncertain future fertility and pregnancy outcomes.

Under fluoroscopic guidance, the catheter was advanced into the left uterine artery which showed a hyperemic uterus with rich blood supply to the right side of the uterus. The distal left uterine artery was embolized using multiple gelfoam pledgets (Fig. 1). When contrast was injected into the right uterine artery, a very vascular uterus as well as a tangle of abnormal-appearing vessels at the superior aspect of the posterior midline consistent with an arteriovenous malformation measuring $2-2.5 \mathrm{~cm}$ in diameter was demonstrated. The catheter was advanced into the distal uterine artery beyond the origin of the anastomoses of the ovarian artery and $1 \mathrm{cc}$ of embospheres $(500-700 \mu \mathrm{m}$, Biosphere 

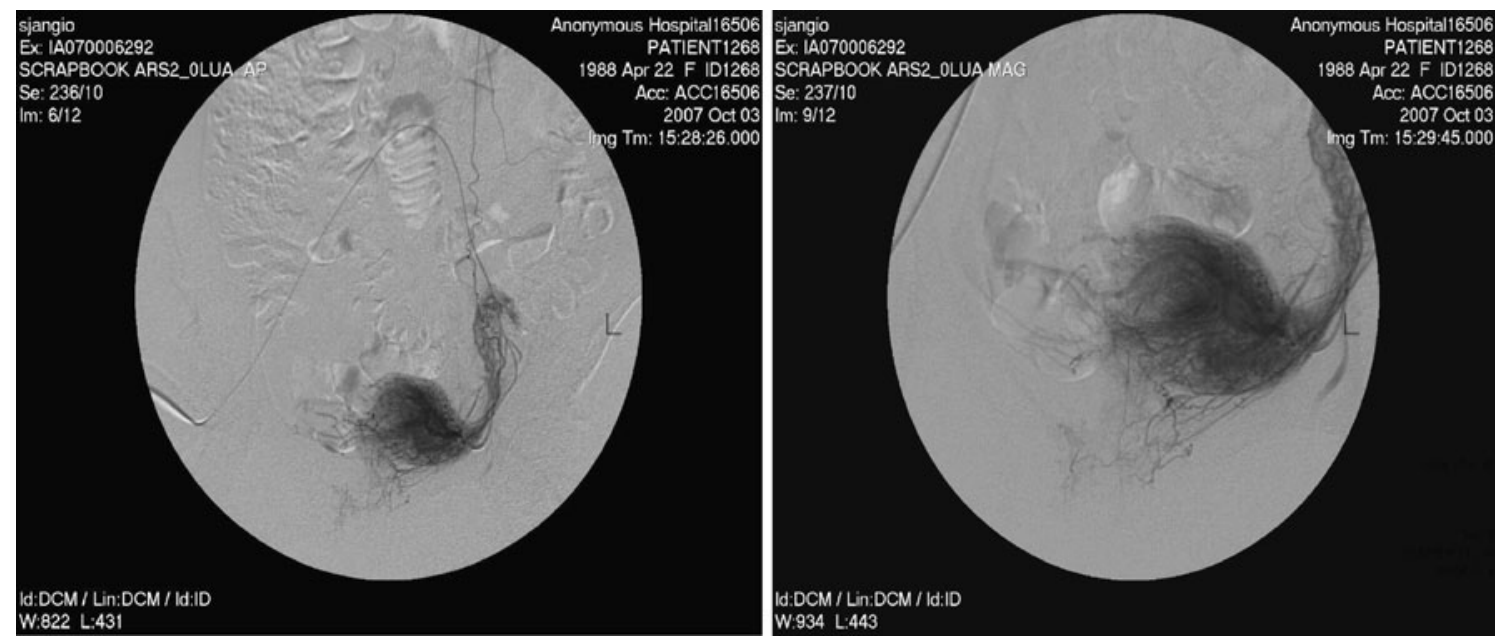

Fig. 1 Left uterine artery embolization of uterine arteriovenous malformation

Medical, Rockland, MA, USA) was used to embolize the artery. The catheter was then pulled back and the more proximal uterine artery was embolized with multiple gelfoam pledgets. Repeat angiography showed occlusion of the distal uterine artery but patency of the proximal uterine artery.

Within 1 month of embolization, the patient had a regular menstrual period and became pregnant on her next cycle. Her pregnancy was monitored by her own obstetrician during the first trimester and she was subsequently referred to our own maternal fetal medicine clinic at 22 weeks gestational age. Initial ultrasound showed a posteriorly implanted placenta with normal uterine artery blood flow and normal fetal growth. Subsequent MRI at

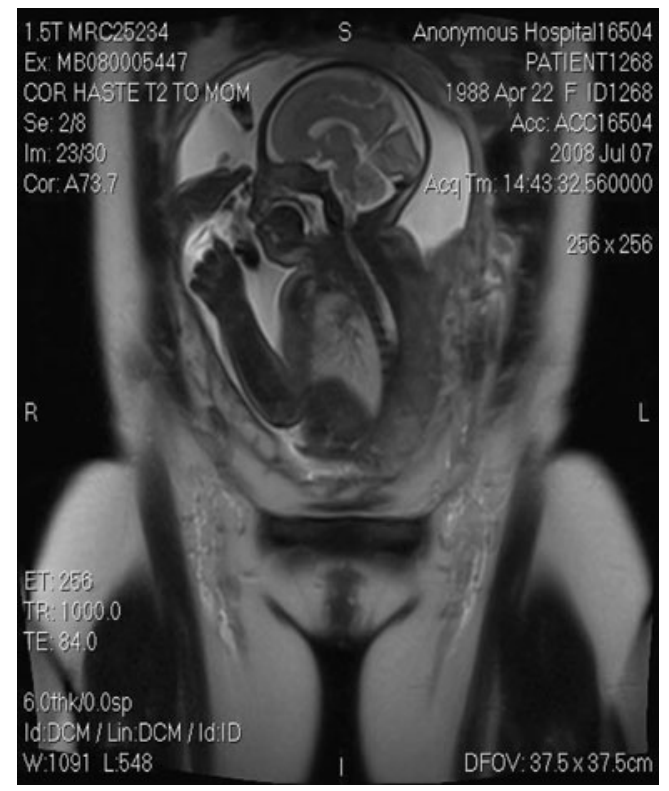

Fig. 2 MR at 34 weeks gestation showing appropriate fetal growth and amniotic fluid
34 weeks showed the placenta predominantly implanted on the posterior aspect of the uterus, overlying the previous A$\mathrm{V}$ malformation site. There was no evidence of placenta accreta or percreta, and the volume of amniotic fluid was adequate (Figs. 2 and 3). Ultrasound showed the estimated fetal weight to be in the 38th percentile with adequate amniotic fluid volume. The umbilical artery Doppler flow was at the 95th percentile. She had no episodes of bleeding and reported adequate fetal movements. She was induced at 39 weeks gestational age, and she delivered a healthy female infant weighing 2,954 g with an Apgar score of 9 and 9 at 1 and $5 \mathrm{~min}$, respectively. The placenta was delivered intact with gentle traction on the cord and fundal stimulation. A small first-degree perineal tear was repaired and the estimated blood loss was less than $500 \mathrm{cc}$. She remained on our post-partum ward for 2 days and did not experience any degree of post-partum hemorrhage.

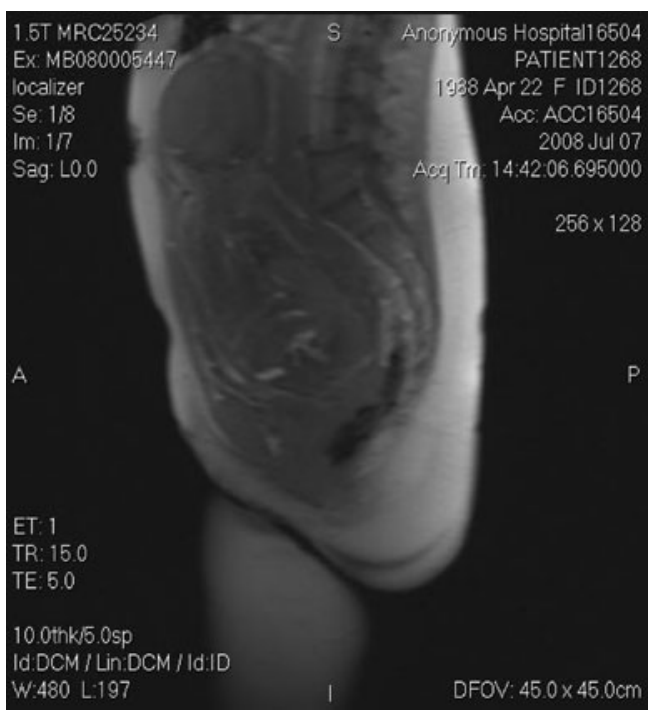

Fig. $3 \mathrm{MR}$ at 34 weeks gestation showing posterior placenta 


\section{Discussion}

Arteriovenous malformations are rare and can cause serious abnormal uterine bleeding. Uterine artery embolization is now an established minimally invasive treatment for a number of uterine disorders including AVM for women who wish to preserve their fertility or who are poor surgical candidates [20-22].

As a rule, uterine artery embolization has been low on the list of treatment options for intractable uterine hemorrhage in women of reproductive age who wish to preserve fertility because of fear that the uterine vasculature may be permanently altered and compromise fertility and pregnancy outcomes. In addition, it is thought that UAE may result in abnormal placentation in future pregnancies resulting in miscarriages, premature births or placenta previa, accreta, and increta.

However, it has been shown that following laparoscopic uterine artery occlusion [23], and uterine artery embolization with particles [24], the uterus actually reperfuses itself and escapes ischemia and necrosis using collateral blood circulation through the broad ligament and ovarian and vaginal arteries [23]. Furthermore, several studies have shown that pregnancy rates and outcomes after UAE for uterine fibroids may not be different than those following myomectomy [25-28]. Pron et al. reported 24 completed pregnancies in 21 women amongst 555 women who had UAE (median age 35 years, range $27-42$ years). Although 164 women reported a desire for future pregnancy before embolization, only 35 women reported that they were trying to conceive at the 1-year follow-up telephone interview for a pregnancy rate of $60 \%$. Three of these women had abnormal placentation; two placenta previa (one partial accreta), and one placenta membranacea with accreta resulting in cesarean hysterectomy. The authors concluded: "After UAE, women were able to conceive and most resulted in term deliveries and appropriately grown newborns. Close monitoring of placental status however is recommended" [26].

Walker et al. reported on over 1,700 women with fibroids embolized from December 1996 to December 2007. Seventy of 130 women seeking pregnancy achieved 94 pregnancies (mean age 38.6 years); a pregnancy rate of $53.8 \%$. The authors concluded that "it is scientifically invalid as is often stated by various bodies and in areas of the literature to claim that no patient wishing to become pregnant should have UAE. In addition, the authors found that pregnancy outcomes after UAE were similar to myomectomy and general population for a given age" [27]. However, since the hemodynamics in cases of UAE for fibroids and AVM are different, the reproductive outcomes following UAE for fibroids and AVM may also be different. Although none of the studies on UAE for fibroids was designed to evaluate fertility and pregnancy outcomes, all studies suggest that the pregnancy rate after uterine artery embolization for symptomatic fibroids may be somewhere between $30 \%$ and $64 \%$. The range of this pregnancy rate is remarkably similar to that reported after myomectomy by any method. For example, a meta-analysis of non-randomized prospective studies on pregnancy after abdominal myomectomy reported an overall pregnancy rate of 57\% [29], while a review of 15 case series reported an overall pregnancy rate of $51.5 \%$ (11\% to $71 \%)$ after laparoscopic myomectomy [30]. Furthermore, a randomized trial of laparoscopic versus laparotomy myomectomy reported pregnancy rates of $54 \%$ vs. $57 \%[31,32]$.

\section{Conclusions}

In the present case, a successful term pregnancy and vaginal delivery was achieved following UAE for treatment of a symptomatic arteriovenous malformation of the uterus. Since this is an extremely rare condition, allowing limited clinical exposure and experience, there may be an underlying reluctance by general practitioners to treat these cases with uterine artery embolization for fear of compromising future fertility and pregnancies. However, data from the 20 pregnancies embolized for uterine AVM cited in the present report and embolization for uterine fibroids indicate that such fears may unfounded since pregnancy rates and outcomes may not be compromised after UAE.

\section{References}

1. Chien S-C, Tseng S-C, Hwa H-L, Wei M-C (2007) Immediate postpartum haemorrhage caused by rupture of uterine arteriovenous malformation. Aust N Z J Obstet Gynecol 47(3):252-254

2. Uchide K, Suzuki N, Murakami K, Terada S, Inoue M (1998) Uterine arteriovenous malformation as a cause of immediate postpartum hemorrhage. Acta Obstet Gynecol Scand 77(5):577-580

3. Kelly S, Belli A, Campbell S (2003) Arteriovenous malformation of the uterus associated with secondary postpartum hemorrhage. Ultrasound Obstet Gynecol 21:602-605

4. Arredondo-Soberon F, Loret de Mola J, Shlansky-Goldberg R, Tureck R (1997) Uterine arteriovenous malformation in a patient with recurrent pregnancy loss and a bicornuate uterus. J Reprod Med 42(4):239-243

5. Gopal M, Goldberg J, Klein T, Fossum GT (2003) Embolization of a uterine arteriovenous malformation followed by a twin pregnancy. Obstet Gynecol 102:696-698

6. Rosa e silva JC, de Aguiar FM, de Sa J, Rosa e Silva AC et al (2008) Conservative management of large uterine arteriovenous malformation: case report. Fertil Steril 90:2406-2407

7. Chapman DR, Lutz MH (1985) Report of a successful delivery after non-surgical management of a choriocarcinoma-related pelvic arteriovenous fistula. Am J Obstet Gynecol 153:155-157 
8. Poppe W, Van Assche FA, Wilms G, Favril A, Baert A (1987) Pregnancy after transcatheter embolization of a uterine arteriovenous malformation. Am J Obstet Gynecol 156:1179-1180

9. Tacchi D, Loose HW (1988) Successful pregnancy after selective embolization of a post-molar vascular malformation. Case report. BJOG 95:814-817

10. Chow TWP, Nwosu EC, Gould DA, Richmond DH (1995) Pregnancy following successful embolization of a uterine vascular malformation. BJOG 102:166-168

11. Gaens J, Desnyder L, Raat H, Stockx L, Wilms G, Baert AL (1996) Selective transcatheter embolization of a uterine arteriovenous malformation with preservation of the reproductive capacity. J Belge Radiol 79:210-211

12. Kelly FW (2001) Forceps delivery after molar malignancy in a woman with arteriovenous malformation. A case report. J Reprod Med 46:1013-1016

13. Lin AKP, Agarwal R, Newlands ES, Barrett NK, Mitchell AWM (2002) Embolization of bleeding residual uterine vascular malformations in patients with treated gestational trophoblastic tumors. Radiology 222:640-644

14. Garner EI, Lipson E, Bernstein MR, Goldstein DP, Berkowitz RS (2003) Successful term pregnancy after selective arterial embolization of symptomatic arteriovenous malformation in the setting of gestational trophoblastic tumor. Gynecol Oncol 88:69-72

15. Chia YN, Yap C, Tan BS (2003) Pregnancy following embolization of uterine arteriovenous malformation-a case report. Ann Acad Med Singap 32:658-660

16. Amagada JO, Karanjgaokar V, Wood A, Wiener JJ (2004) Successful pregnancy following two uterine artery embolisation procedures for arteriovenous malformation. J Obstet Gynaecol 24:86-87

17. Tsai CC, Cheng YF, Changchien CC, Lin H (2006) Successful term pregnancy after selective embolization of a large posterior uterine arteriovenous malformation. Int $\mathrm{J}$ Gynecol Cancer 16 (suppl. 1):439-441

18. Delotte J, Chevallier P, Benoit B, Castillon JM, Bongain A (2006) Pregnancy after embolization therapy for uterine arteriovenous malformation. Fertil Steril 85:228.el-6

19. Hasegawa T, Yamakawa Y, Ota S, Kamei T, Tateno M (2008) Delivery by cesarean section after embolization for vaginal arteriovenous malformation. Gynecol Obstet Invest 65:24-28

20. Chan CC, Chu F, Pun TC (2003) Treating recurrent uterine arteriovenous malformation with uterine artery embolization. A case report. J Reprod Med 48:905-907
21. Halperin R, Schneider D, Maymoy R et al (2007) Arteriovenous malformation after uterine curettage: a report of 3 cases. J Reprod Med 52:445-449

22. Patel S, Potti S, Jaspar D, Domdou V (2009) Embolization of uterine arteriovenous malformation for treatment of menorrhagia. Arch Gynecol Obstet 279(2):229-232

23. Lichtinger M, Burbank F, Hallson L, Herbert S et al (2003) The time course of myometrial ischemia and reperfusion after laparoscopic uterine occlusion-theoretical implications. J Am Assoc Gynecol Laparosc 10(4):553-566

24. Kroenke TJ, Scheurig C, Taupitz M, Kluner C, Hamm B, Gauruder-Burmester A (2006) Effect of UAE for fibroids on uterine and fibroid perfusion: evidence of transient uterine ischemia at MR imaging [Abstract]. J Vasc Interv Radiol 17: $\mathrm{S} 12$

25. Goldberg T, Pereira L, Berghella V et al (2004) Pregnancy outcomes after treatment for fibromyomota: uterine artery embolization versus laparoscopic myomectomy. Am J Obstet Gynecol 191:18-21

26. Pron G, Mocarski E, Bennett J, Vilos GA, Common A, Vanderburgh L (2005) Pregnancy after uterine artery embolization for leiomyomata: The Ontario Multicentre Trial. Obstet Gynecol 105:67-76

27. Walker WJ, Carpenter TT, McDowell S, Neilsen R. Joint RCOG/ BSGE Meeting, April 17-18, 2008, London, UK

28. Mara M, Maskova J, Fucikova Z, Kuzel D, Belsan T, Sosna O (2008) Midterm clinical and first reproductive results of a randomized controlled trial comparing uterine fibroid embolization and myomectomy. Cardiovasc Interv Radiol 31(1):73-85

29. Vercellini P, Maddalena S, De Giorgi O, Crosignani PG (1998) Abdominal myomectomy for infertility: a comprehensive review. Hum Reprod 13:873-879

30. Hurst BS, Mathews ML, Marshbury PB (2005) Laparoscopic myomectomy for symptomatic uterine myomas. Fertil Steril $83: 1-23$

31. Seracchioli R, Rossi S, Govovi F, Rossi E, Venturoli S, Bulletti C, Flamini C (2000) Fertility and obstetric outcome after laparoscopic myomectomy of large myomata: a randomized comparison with abdominal myomectomy. Hum Reprod 15:2663-2668

32. Somigliana E, Vercellini P, Daguati R, Pasin R, De Giorgi O, Crosignani PG (2007) Fibroids and female reproduction: a critical analysis of the evidence. Hum Reprod Updat 13 (5):465-476 